\title{
Phase II study of carfilzomib, thalidomide, and low-dose dexamethasone as induction and consolidation in newly diagnosed, transplant eligible patients with multiple myeloma; the Carthadex trial
}

\begin{abstract}
Ruth Wester, ${ }^{1}$ Bronno van der Holt, ${ }^{2}$ Emelie Asselbergs, ${ }^{1}$ Sonja Zweegman, ${ }^{3}$ Marie Jose Kersten, ${ }^{2}$ Edo Vellenga, ${ }^{4}$ Marinus van Marwijk Kooy, ${ }^{5}$ Okke de Weerdt, ${ }^{6}$ Monique Minnema, ${ }^{7}$ Sarah Lonergan, ${ }^{1}$ Antonio Palumbo, ${ }^{8}$ Henk Lokhorst, ${ }^{3}$ Annemiek Broijl ${ }^{1}$ and Pieter Sonneveld ${ }^{1}$

${ }^{1}$ Department of Hematology, Erasmus MC Cancer Institute, Rotterdam, the Netherlands; ${ }^{2}$ HOVON Data Center, Department of Hematology, Erasmus MC Cancer Institute, Rotterdam, the Netherlands; ' ${ }^{3}$ Department of Hematology, Amsterdam UMC, Amsterdam, the Netherlands; ${ }^{4}$ Department of Hematology, University Medical Center Groningen, University of Groningen, the Netherlands; ${ }^{5}$ Department of Hematology, Isala Clinics, Zwolle, the Netherlands; ${ }^{\circ}$ Department of Internal Medicine, St. Antonius Hospital, Nieuwegein, the Netherlands; ' Department of Hematology, UMC Utrecht Cancer Center, Utrecht, the Netherlands and ${ }^{8}$ Department of Hematology, University of Torino, Torino, Italy
\end{abstract}

\section{ABSTRACT}

T his is a phase II dose escalation trial of carfilzomib in combination with thalidomide and dexamethasone for induction and consolidation in transplant-eligible patients with newly diagnosed multiple myeloma (NDMM). The results of four dose levels are reported. Induction therapy consisted of four cycles of carfilzomib $20 / 27 \mathrm{mg} / \mathrm{m}^{2}$ $(\mathrm{n}=50), 20 / 36 \mathrm{mg} / \mathrm{m}^{2}(\mathrm{n}=20), 20 / 45 \mathrm{mg} / \mathrm{m}^{2}(\mathrm{n}=21)$, and $20 / 56 \mathrm{mg} / \mathrm{m}^{2}$ $(\mathrm{n}=20)$ on days $1,2,8,9,15,16$ of a 28 -day cycle; thalidomide $200 \mathrm{mg}$ on day 1 through 28 and dexamethasone $40 \mathrm{mg}$ weekly. Induction therapy was followed by high-dose melphalan and autologous stem cell transplantation and consolidation therapy with four cycles of carfilzomib, thalidomide and dexamethasone in the same schedule except a lower dose of thalidomide $(50 \mathrm{mg})$. Very good partial response rate or better and complete response rate or better after induction therapy were $65 \%$ and $18 \%$, respectively, increasing to $86 \%$ and $63 \%$, respectively, after consolidation therapy. In all cohorts combined, after a median follow up of 58.7 months, median progression-free survival was 58 months (95\% CI: 45-67 months). Median overall survival was 83 months (95\% CI: 83 months-not reached). Grade 3/4 adverse events consisted mainly of infections, respiratory disorders, skin and vascular disorders in $11 \%, 8 \%$, $9 \%$, and $9 \%$, respectively. Grade 3 polyneuropathy was only reported in one patient. Cardiac events were limited: grade $3 / 4$ in $5 \%$ of patients. Carfilzomib, thalidomide and dexamethasone as induction and consolidation treatment after high-dose melphalan and autologous stem cell transplantation is highly efficacious and safe in transplant-eligible patients with NDMM. This study was registered as \#NTR2422 at http://www.trialregister.nl

\section{Introduction}

Survival rates in patients with multiple myeloma (MM) have significantly improved during the last decades. However, eventually the majority of patients progress and the need for new therapeutic approaches remains. In transplant-eligible patients with newly diagnosed multiple myeloma (NDMM), depth of

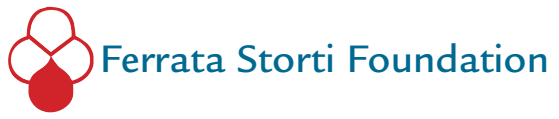

Haematologica 2019
Volume 104(11):2265-2273

\section{Correspondence:}

RUTH WESTER

r.wester@erasmusmc.nl.

Received: September 2, 2018

Accepted: March 28, 2019.

Pre-published: April 4, 2019.

doi:10.3324/haematol.2018.205476

Check the online version for the most updated information on this article, online supplements, and information on authorship \& disclosures: www.haematologica.org/content/104/11/2265

(C)2019 Ferrata Storti Foundation

Material published in Haematologica is covered by copyright. All rights are reserved to the Ferrata Storti Foundation. Use of published material is allowed under the following terms and conditions:

https://creativecommons.org/licenses/by-nc/4.0/legalcode. Copies of published material are allowed for personal or internal use. Sharing published material for non-commercial purposes is subject to the following conditions: https://creativecommons.org/licenses/by-nc/4.0/legalcode, sect. 3. Reproducing and sharing published material for commercial purposes is not allowed without permission in writing from the publisher. 
response before and after high-dose melphalan/autologous stem cell transplantation (HDM/ASCT) is associated with improvement in progression-free survival (PFS) and overall survival (OS). ${ }^{1-5}$ Therefore, it is important to select the appropriate induction and consolidation therapy in order to achieve a maximum response after ASCT and to maintain or even increase this response during consolidation therapy and thereafter.

Standard induction treatment consists of triple therapy including a proteasome inhibitor, and/or an immunomodulatory drug and dexamethasone. The combination of bortezomib, thalidomide and dexamethasone (VTD) has been extensively investigated in transplant-eligible patients with NDMM.$^{6-8}$ However, treatment with bortezomib is associated with higher rates of polyneuropathy (PN) and a consequent discontinuation of treatment. ${ }^{7,8}$ It is important to use a regimen that is highly effective and safe in patients with NDMM. This could improve treatment adherence and subsequently outcome after induction and consolidation therapy.

Carfilzomib is a selective proteasome inhibitor with irreversible binding to the constitutive proteasome and immunoproteasome. It is approved in the United States and in Europe as a single-agent for the treatment of patients with relapsed and/or refractory MM (RRMM). Carfilzomib is approved at a dose of $27 \mathrm{mg} / \mathrm{m}^{2}$ in combination with lenalidomide and dexamethasone in RRMM based on the data from the ASPIRE trial showing a superior PFS of median 26.3 months versus 17.4 months when patients were treated with lenalidomide/dexamethasone. ${ }^{9}$ Carfilzomib is also approved at a dose of $56 \mathrm{mg} / \mathrm{m}^{2}$ in combination with dexamethasone, based on data from the ENDEAVOR trial showing a superior PFS over bortezomib/dexamethasone of median 18.7 months versus 9.4 months $(P<0.0001) .{ }^{10}$ Previous trials showed that the incidence of $\mathrm{PN}$ with carfilzomib is lower compared to bortezomib. ${ }^{9-11}$

Carfilzomib has not yet been approved for treatment in NDMM in Europe. Recent trials in patients with NDMM, using different treatment regimens, showed high response rates. ${ }^{12-15} \mathrm{~A}$ phase I/II trial of patients with NDMM treated with carfilzomib at a maximum dose of $36 \mathrm{mg} / \mathrm{m}^{2}$ combined with lenalidomide and low-dose dexamethasone showed a very good partial response (VGPR) rate of $81 \%$. PFS at 24 months was $92 \% .{ }^{12}$

We previously initiated a Phase II dose-escalation trial of carfilzomib combined with thalidomide and dexamethasone. The combination of a proteasome inhibitor and an immunomodulating agent has a proven synergystic effect. ${ }^{6}$ Moreover, thalidomide is an effective and affordable drug available in many countries.

In NDMM, there is no consensus as to the optimum dose level of carfilzomib, implicating the need for dosefinding trials. The goal of this trial was to investigate the efficacy of this combination at various dose levels of carfilzomib in NDMM. Results of the first three cohorts of this Carthadex trial were published in 2015. ${ }^{11}$ Overall response rate (ORR) after induction therapy was $90 \%$ with a VGPR rate of $68 \%$. PFS at 36 months was $72 \%$. The combination of carfilzomib, thalidomide and dexamethasone (KTd) was well tolerated. ${ }^{11}$ Four different dose levels were included in this trial based on the hypothesis that a higher dose level induces a higher response rate..$^{12,16}$ We report herein the results of our dose escalation cohorts with a long follow up. This is the first study using
KTd for both induction and consolidation therapy and comparing different dose levels.

\section{Methods}

\section{Patients}

Transplant-eligible patients with NDMM, aged 18-65 years, were eligible for enrollment. Patients were required to have a World Health Organization (WHO) performance status of 0-3; WHO 3 was allowed only when caused by MM and not by co-morbid conditions.

Patients were ineligible if they had grade $3 / 4$ polyneuropathy (PN) or grade 2 painful $\mathrm{PN}$, severe cardiac dysfunction (New York Heart Association class II-IV), known intolerance of thalidomide, systemic amyloid light-chain amyloidosis, nonsecretory MM, Waldenström macroglobulinemia or IgM MM, creatinine clearance $<15 \mathrm{~mL} / \mathrm{min}$, absolute neutrophil count $<1.0 \times 10^{9} / \mathrm{L}$, platelets $<75 \times 10^{9} / \mathrm{L}$, hemoglobin $<4.9 \mathrm{mmol} / \mathrm{L}$, active malignancy during the past five years with the exception of basal carcinoma of the skin or stage 0 cervical carcinoma.

This independent investigator-initiated multi-institutional study was conducted in accordance with the Declaration of Helsinki, the International Conference on Harmonization Guidelines for Good Clinical Practice, and the European Clinical Trial Directive as implemented under Dutch law. The protocol was approved by institutional review boards and ethics committees. All patients gave informed consent.

\section{Study design and treatment}

This single-arm, open-label, phase II trial was conducted at eight hematology centers. Patients were treated with four cycles KTd of a 28-day cycle for induction therapy. Carfilzomib was administered in a 30-minute infusion. The dose in the first dosing cohort was $20 \mathrm{mg} / \mathrm{m}^{2}$ on days 1 and 2 and was escalated to a dose of $27 \mathrm{mg} / \mathrm{m}^{2}$ on days $8,9,15$ and 16 of cycle 1 and on days $1,2,8,9,15$ and 16 of cycles $2-4$. Thalidomide $200 \mathrm{mg}$ was given orally on days 1 through 28 and dexamethasone $40 \mathrm{mg}$ was given orally on days $1,8,15$ and 22 . Induction therapy was followed by stem cell harvest after cyclophosphamide priming $\left(2-4 \mathrm{mg} / \mathrm{m}^{2}\right.$ i.v. $)$ and daily $10 \mu \mathrm{g} / \mathrm{kg}$ granulocyte colony-stimulating factor. Hereafter, patients received high-dose melphalan (HDM, $200 \mathrm{mg} / \mathrm{m}^{2}$ ) and ASCT followed by consolidation treatment with four cycles of KTd in the same schedule and dose as induction treatment except that the dose of thalidomide was 50 $\mathrm{mg}$ instead of $200 \mathrm{mg}$. The dose of carfilzomib was escalated to $20 / 36 \mathrm{mg} / \mathrm{m}^{2}, 20 / 45 \mathrm{mg} / \mathrm{m}^{2}$ and $20 / 56 \mathrm{mg} / \mathrm{m}^{2}$ in cohorts 2,3 and 4 , respectively. Under the study protocol, patients were required to maintain adequate hydration. In addition, patients were treated prophylactically with antibiotics (ciprofloxacin or another fluoroquinolone) and with antiviral medication (acyclovir or a similar anti varicella agent). All patients received antithrombotic prophylaxis with aspirin in case of low thrombotic risk or with low-molecular-weight heparin in patients with pre-existing thrombotic risk factors. ${ }^{17}$

The primary end point of the study was response after induction therapy and overall response, specifically complete response (CR) and VGPR. Secondary end points were efficacy and safety, maximum tolerated dose (MTD), dose limiting toxicities (DLT), PFS and overall survival (OS). PFS was defined as time from registration to progression or death, whichever came first. OS was calculated from registration to death from any cause; patients still alive at last contact were censored.

This study was registered as \#NTR2422 at http://www.trialregister.nl. 


\section{Assessments}

Treatment responses and disease progression were assessed by study investigators and were classified according to International Myeloma Working Group (IMWG) Uniform Response Criteria, with categories for CR, VGPR, and partial response (PR). ${ }^{18}$ Toxicity was assessed according to the National Cancer Institute Common Terminology Criteria of Adverse Events version 4.0. ${ }^{19}$ Bone marrow analysis was performed at diagnosis to quantify myeloma cell involvement. Molecular, cytogenetic and fluorescence in situ hybridization (FISH) studies were performed on these samples. $\mathrm{CD} 138^{+}$purified MM cells were used to determine the presence of the following cytogenetic abnormalities: $t(4 ; 14)(p 16 ; q 32)$, $\mathrm{t}(14 ; 16)(q 32 ; \mathrm{q} 32), \operatorname{del}(13 q), \operatorname{del}(17 \mathrm{p}), 1 \mathrm{p} / \mathrm{q}$ abnormalities, numerical abnormalities of chromosome 9 or 11, and complex cytogenetic abnormalities. ${ }^{11}$

\section{Statistical analysis}

This study was designed to investigate whether induction treatment with KTd warrants further investigation in future trials. The intention-to-treat principle was used for all analyses, restricted to eligible patients. A CR + VGPR rate lower than 25\% after induction treatment, was considered too low to warrant further investigation in future trials; however, if the CR + VGPR rate was higher than $45 \%$, therapeutic activity was considered sufficiently high to support further investigation. To reject the null hypothesis in favor of the alternative hypothesis with power $1-\beta=0.80$ (two-sided significance level $\alpha=0.05$ ), a minimum of 41 patients should be included. A 95\% confidence interval (CI) was constructed around the CR + VGPR rate after induction treatment and the null hypothesis was rejected if the lower boundary was larger than $25 \%$.

Predefined subgroup analyses were performed to investigate the effect of risk status, using cytogenetic/FISH criteria, International Staging System (ISS) stage and revised (R)-ISS stage, on response and survival. In this trial, patients were considered to be high-risk if they had t(4;14) and/or del(17p) and/or add(1q) and/or ISS stage III.

Continuous and categorical data were summarized with descriptive statistics. Survival end points were estimated using the Kaplan-Meier method, and 95\%CI were constructed. The logrank was used to evaluate differences in PFS and OS between subgroups. Statistical analysis was performed using Stata v15.1 software (StataCorp, College Station, TX, USA).

\section{Results}

\section{Patients and treatment}

One hundred and eleven patients were enrolled between September $16^{\text {th }}, 2010$ and December $30^{\text {th }}, 2013$. The analysis was based on data available as of February $27^{\text {th }}, 2018$ with a median follow up of 58.7 months (range: 25.1-88.0 months). Four different dose levels were investigated (27 $\mathrm{mg} / \mathrm{m}^{2}, \mathrm{n}=50 ; 36 \mathrm{mg} / \mathrm{m}^{2}, \mathrm{n}=20 ; 45 \mathrm{mg} / \mathrm{m}^{2}, \mathrm{n}=21 ; 56 \mathrm{mg} / \mathrm{m}^{2}$, $\mathrm{n}=20$ ). Baseline demographics and disease characteristics are shown in Table 1. Median age was 58 years (range: 2966 years) and the male/female distribution $61 \% / 39 \%$. Nine percent of patients had an R-ISS stage 3 and in $9 \%$ of patients R-ISS stage was unknown, mainly due to missing cytogenetics. A total of $39 \%$ of patients were classified as high-risk based on cytogenetics and ISS stage; $41 \%$ of patients were classified as standard risk. In $20 \%$ of patients, risk status was unknown, mainly due to missing cytogenetics. Seven patients had a history of grade $1 / 2 \mathrm{PN}$ and two patients a grade $3 \mathrm{PN}$ at diagnosis; in nine patients, baseline assessment of $\mathrm{PN}$ was missing at enrollment. A total of $5 \%$ of patients had renal insufficiency with a creatinine $\geq 177$ $\mu \mathrm{mol} / \mathrm{L}$ at diagnosis.

All 111 patients started induction therapy with KTd (Figure 1). Six patients discontinued treatment because of the following adverse events (AE): grade 3 rash (carfilzomib $27 \mathrm{mg} / \mathrm{m}^{2}$ ), grade 2 fever with sepsis (carfilzomib 27 $\mathrm{mg} / \mathrm{m}^{2}$ ), grade 1 hyponatremia (carfilzomib $27 \mathrm{mg} / \mathrm{m}^{2}$ ), grade 2 exanthema (carfilzomib $27 \mathrm{mg} / \mathrm{m}^{2}$ ), grade 3 congestive heart failure (carfilzomib $27 \mathrm{mg} / \mathrm{m}^{2}$ ), grade 3 pneumonitis (carfilzomib $36 \mathrm{mg} / \mathrm{m}^{2}$ ), grade 3 drug reaction with eosinophilia and systemic symptoms (Dress syndrome) (carfilzomib $56 \mathrm{mg} / \mathrm{m}^{2}$ ). One patient appeared not eligible for further treatment and two patients discontinued treatment due to progressive disease. Out of 111 patients, 102 $(92 \%)$ continued treatment with high-dose cyclophosphamide and stem cell collection. Stem cell collection was successful in 100 of 102 patients with a median $\mathrm{CD} 34^{+}$yield of $5.5 \times 10^{3}$. A total of 98 patients $(88 \%)$ continued treatment with a single HDM $\left(200 \mathrm{mg} / \mathrm{m}^{2}\right)$ and ASCT. Four patients were not eligible for HDM: one because of insufficient $\mathrm{CD}_{34}^{+}$yield and three because of progression of disease after stem cell collection. After treatment with HDM and ASCT, 94 patients (85\%) initiated consolidation therapy. Four patients were not eligible for consolidation treatment because of progression of disease $(n=1)$, a delayed hematologic recovery after ASCT $(n=1)$, non-related disease $(n=1)$, and uncontrolled pain after ASCT $(n=1)$. Nine patients discontinued consolidation treatment because of progressive disease $(n=2)$, thrombotic thrombocytopenic purpura (TTP) $(\mathrm{n}=1)$, a TTP-like syndrome $(\mathrm{n}=1)$, overall worsening of condition $(n=1)$, grade 3 fatigue $(n=1)$, refusal of further treatment $(n=2)$, and persisting $\mathrm{PN}(\mathrm{n}=1)$. A total of 83 patients $(75 \%)$ completed all four consolidation cycles.

\section{Efficacy}

Table 2 shows response to induction, HDM/ASCT and consolidation therapy. Response according to risk group and R-ISS is shown in Table 3. Overall response after induction therapy in all 111 patients was 93\% with a CR rate of $18 \%$. The $\geq$ VGPR rate after induction therapy was $65 \%(95 \% \mathrm{CI}: 55-74 \%)$ leading to rejection of the null hypothesis, as the $95 \% \mathrm{CI}$ is above $25 \%$. The $\geq \mathrm{VGPR}$ rate increased to $77 \%$ after HDM/ASCT and to $86 \%$ after consolidation therapy. ORR increased to $94 \%$ after consolidation therapy. CR rate after induction therapy between the four different dose levels was comparable and increased after consolidation therapy. At the three highest dose levels, CR rate after consolidation therapy was higher in comparison to the lowest dose level $(75 \%, 67 \%$ and $65 \%$ vs. $56 \%$, respectively); however, this was not statistically significant (test for trend, $P=0.39 ; \chi^{2}$ test, $27 \mathrm{mg} / \mathrm{m}^{2}$ vs. 36-56 $\mathrm{mg} / \mathrm{m}^{2}, P=0.16$ ). Response after consolidation treatment between standard risk patients and high-risk patients (defined by ISS stage and cytogenetics) was similar with CR rates of $67 \%$ versus $58 \%$. Response after consolidation therapy according to R-ISS stage (I, II and III) was comparable with CR rates of $73 \%, 57 \%$ and $60 \%$, respectively.

Median PFS in all 111 patients was 58 months $(95 \% \mathrm{CI}$ : 45-67 months). Dose level was not associated with PFS. Median PFS in high-risk patients was worse compared to standard risk patients (42 vs. 60 months; $P=0.006$ ), while a higher R-ISS stage was also associated with a worse PFS $(P=0.04)$ (Figure 2).

Median OS was 83 months and 5-year OS was 76\% (95\% CI: 66-83\%) (Figure 3). Dose level and risk status were not associated with OS. 
Safety

Any grade hematologic toxicity occurred in $15 \%$ of patients. Grade 3/4 hematologic toxicity occurred in 10\% of patients. At dose level $27 \mathrm{mg} / \mathrm{m}^{2}, 36 \mathrm{mg} / \mathrm{m}^{2}, 45 \mathrm{mg} / \mathrm{m}^{2}$ and $56 \mathrm{mg} / \mathrm{m}^{2}$, grade $3 / 4$ hematologic toxicity occurred in
$12 \%, 10 \%, 10 \%$ and $10 \%$, respectively. Main grade $3 / 4$ non-hematologic toxicity consisted of infections, respiratory disorders, skin and vascular disorders in $11 \%, 8 \%$, $9 \%$, and $9 \%$, respectively. There was a gradual increase in grade $3 / 4$ infections from lower to higher doses of carfil-

Table 1. Baseline characteristics.

\begin{tabular}{|c|c|c|c|c|c|}
\hline Characteristic & $20 / 27 \mathrm{mg} / \mathrm{m}^{2}$ & $20 / 36 \mathrm{mg} / \mathrm{m}^{2}$ & $20 / 45 \mathrm{mg} / \mathrm{m}^{2}$ & $20 / 56 \mathrm{mg} / \mathrm{m}^{2}$ & All patients \\
\hline Patients, $n$ & 50 & 20 & 21 & 20 & 111 \\
\hline Male, n (\%) & $34(68)$ & $11(55)$ & $16(76)$ & $7(35)$ & $68(61)$ \\
\hline Age, median (range), years & $58(29-66)$ & $58(47-64)$ & $56(33-65)$ & $58(37-65)$ & $58(29-66)$ \\
\hline $\begin{array}{l}\text { ISS stage, n (\%) } \\
1 \\
2 \\
3 \\
\text { Unknown }\end{array}$ & $\begin{array}{c}18(36) \\
20(40) \\
12(24) \\
0(0)\end{array}$ & $\begin{array}{l}5(25) \\
7(35) \\
8(40) \\
0(0)\end{array}$ & $\begin{array}{l}14(67) \\
4(19) \\
2(10) \\
1(5)\end{array}$ & $\begin{array}{l}9(45) \\
7(35) \\
4(20) \\
0(0)\end{array}$ & $\begin{array}{c}46(41) \\
38(34) \\
26(23) \\
1(1)\end{array}$ \\
\hline $\begin{array}{l}\text { R-ISS stage, n (\%) } \\
1 \\
2 \\
3 \\
\text { Unknown }\end{array}$ & $\begin{array}{l}7(14) \\
37(74) \\
2(4) \\
4(8)\end{array}$ & $\begin{array}{l}3(15) \\
10(50) \\
5(25) \\
2(10)\end{array}$ & $\begin{array}{l}10(48) \\
7(33) \\
0(0) \\
4(19)\end{array}$ & $\begin{array}{c}6(30) \\
11(55) \\
3(15) \\
0(0)\end{array}$ & $\begin{array}{l}26(23) \\
65(59) \\
10(9) \\
10(9)\end{array}$ \\
\hline $\begin{array}{l}\text { WHO performance status, } \mathrm{n}(\%) \\
0 \\
1 \\
2 \\
3 \\
\text { Unknown }\end{array}$ & $\begin{array}{l}24(48) \\
20(40) \\
2(4) \\
0(0) \\
4(8)\end{array}$ & $\begin{array}{l}7(35) \\
10(50) \\
1(5) \\
0(0) \\
2(10)\end{array}$ & $\begin{array}{l}11(52) \\
7(33) \\
1(5) \\
2(10) \\
0(0)\end{array}$ & $\begin{array}{l}12(60) \\
8(40) \\
0(0) \\
0(0) \\
0(0)\end{array}$ & $\begin{array}{l}54(49) \\
45(41) \\
4(4) \\
2(2) \\
6(5)\end{array}$ \\
\hline $\begin{array}{l}\text { M-protein isotype, n (\%) } \\
\text { IgA } \\
\text { IgG } \\
\text { IgD } \\
\text { Light-chain disease } \\
\text { Unknown }\end{array}$ & $\begin{array}{l}11(22) \\
30(60) \\
1(2) \\
7(14) \\
1(2)\end{array}$ & $\begin{array}{l}5(25) \\
8(40) \\
1(5) \\
4(20) \\
2(10)\end{array}$ & $\begin{array}{l}4(19) \\
10(48) \\
1(5) \\
6(29) \\
0(0)\end{array}$ & $\begin{array}{l}4(20) \\
11(55) \\
0(0) \\
5(25) \\
0(0)\end{array}$ & $\begin{array}{c}24(22) \\
59(53) \\
3(3) \\
22(20) \\
3(3)\end{array}$ \\
\hline $\begin{array}{l}\text { Genetic abnormalities, n (\%)* } \\
\text { add } 1 q \\
\text { Yes } \\
\text { No } \\
\text { Unknown }\end{array}$ & $\begin{array}{c}5(10) \\
35(70) \\
10(20)\end{array}$ & $\begin{array}{c}4(20) \\
12(60) \\
4(20)\end{array}$ & $\begin{array}{l}2(10) \\
15(71) \\
4(19)\end{array}$ & $\begin{array}{c}7(35) \\
10(50) \\
3(15)\end{array}$ & $\begin{array}{l}18(16) \\
72(65) \\
21(19)\end{array}$ \\
\hline $\begin{array}{l}\mathrm{t}(4 ; 14)(\mathrm{p} 16 ; 32) \\
\text { Yes } \\
\text { No } \\
\text { Unknown }\end{array}$ & $\begin{array}{c}2(4) \\
39(78) \\
9(18)\end{array}$ & $\begin{array}{l}2(10) \\
14(70) \\
4(20)\end{array}$ & $\begin{array}{c}0(0) \\
19(90) \\
2(10)\end{array}$ & $\begin{array}{c}3(15) \\
13(65) \\
4(20)\end{array}$ & $\begin{array}{l}7(6) \\
85(77) \\
19(17)\end{array}$ \\
\hline $\begin{array}{l}\text { del(17p13) } \\
\text { Yes } \\
\text { No } \\
\text { Unknown }\end{array}$ & $\begin{array}{c}3(6) \\
38(76) \\
9(18)\end{array}$ & $\begin{array}{c}2(10) \\
14(70) \\
4(20)\end{array}$ & $\begin{array}{c}1(5) \\
18(86) \\
2(10)\end{array}$ & $\begin{array}{c}1(5) \\
16(80) \\
3(15)\end{array}$ & $\begin{array}{c}7(6) \\
86(77) \\
18(16)\end{array}$ \\
\hline $\begin{array}{l}\mathrm{t}(11 ; 14)(\mathrm{q} 13 ; q 32) \\
\text { Yes } \\
\text { No } \\
\text { Unknown }\end{array}$ & $\begin{array}{c}5(10) \\
36(72) \\
9(18)\end{array}$ & $\begin{array}{c}1(5) \\
15(75) \\
4(20)\end{array}$ & $\begin{array}{l}2(10) \\
17(81) \\
2(10)\end{array}$ & $\begin{array}{c}1(5) \\
15(75) \\
4(20)\end{array}$ & $\begin{array}{c}9(8) \\
83(75) \\
19(17)\end{array}$ \\
\hline $\begin{array}{l}\mathrm{t}(14 ; 16)(\mathrm{q} 32 ; \mathrm{q} 23) \\
\text { Yes } \\
\text { No } \\
\text { Unknown }\end{array}$ & $\begin{array}{c}3(6) \\
38(76) \\
9(18)\end{array}$ & $\begin{array}{c}1(5) \\
15(75) \\
4(20)\end{array}$ & $\begin{array}{c}0(0) \\
19(90) \\
2(10)\end{array}$ & $\begin{array}{c}0(0) \\
16(80) \\
4(20)\end{array}$ & $\begin{array}{c}4(4) \\
88(79) \\
19(17) \\
\end{array}$ \\
\hline $\begin{array}{l}\text { Risk status, n }(\%)^{\dagger} \\
\text { High } \\
\text { Standard } \\
\text { Unknown }\end{array}$ & $\begin{array}{l}19(38) \\
21(42) \\
10(20)\end{array}$ & $\begin{array}{l}10(50) \\
6(30) \\
4(20)\end{array}$ & $\begin{array}{c}4(19) \\
12(57) \\
5(24)\end{array}$ & $\begin{array}{c}10(50) \\
7(35) \\
3(15)\end{array}$ & $\begin{array}{l}43(39) \\
46(41) \\
22(20)\end{array}$ \\
\hline Grade $1 / 2$ PN, n (\%) & $3(6)$ & $2(10)$ & $0(0)$ & $2(10)$ & $7(7)$ \\
\hline
\end{tabular}

PNP,polyneuropathy. *A total of 93 patients were evaluable. The table shows the presence of the genetic abnormality in all four dose levels together and in each dose level separately. 'High-risk: $\mathrm{t}(4 ; 14)$ and/or $17 \mathrm{p}$ - and/or addlq cytogenetic abnormalities and/or ISS stage 3 disease. Standard risk: the remaining patients with available cytogenetics and ISS stage. ${ }^{* N o t}$ recorded in 9 patients. Ktd: carfilzomib, thalidomide and dexamethasone; n: number: HDM + ASCT: high-dose melphalan + autologous stem cell transplantation. n: number; ISS: International Staging System; R-ISS: Revised International Staging System;WHO:World Health Organisation; PN: polyneuropathy. 
zomib (0\%, 5\%, 10\%, and $15 \%$, respectively) and consisting mainly of pneumonia (Online Supplementary Table S1).

Table 4 summarizes cardiac AE. Any grade cardiac AE were reported in $12 \%$ of patients after induction therapy $\left(14 \%\right.$ in carfilzomib $27 \mathrm{mg} / \mathrm{m}^{2}, 15 \%$ in carfilzomib 36 $\mathrm{mg} / \mathrm{m}^{2}, 19 \%$ in carfilzomib $45 \mathrm{mg} / \mathrm{m}^{2}$, and $5 \%$ in carfilzomib $56 \mathrm{mg} / \mathrm{m}^{2}$ ). These cardiac events consisted mainly of grade $1 / 2$ toxicity (11 of 15 events). Five (5\%) grade 3 cardiac AE were reported: three at dose level $27 \mathrm{mg} / \mathrm{m}^{2}$, one at dose level $45 \mathrm{mg} / \mathrm{m}^{2}$, and one at dose level 56 $\mathrm{mg} / \mathrm{m}^{2}$.

Any grade cardiac AE increased to $18 \%$ after consolidation therapy with no reports of grade $4 \mathrm{AE}$ at all four dose levels, $\left(18 \%\right.$ in carfilzomib $27 \mathrm{mg} / \mathrm{m}^{2}, 15 \%$ in carfilzomib $36 \mathrm{mg} / \mathrm{m}^{2}, 19 \%$ in carfilzomib $45 \mathrm{mg} / \mathrm{m}^{2}$, and $15 \%$ in carfilzomib $56 \mathrm{mg} / \mathrm{m}^{2}$ ). These cardiac events consisted mainly of grade $1 / 2$ toxicity (14 of 19 events). Five (5\%) grade 3 cardiac AE were reported.

Nine patients $(8 \%)$ developed hypertension during treatment (carfilzomib $27 \mathrm{mg} / \mathrm{m}^{2}, \mathrm{n}=3$; carfilzomib 36 $\mathrm{mg} / \mathrm{m}^{2}, \mathrm{n}=3$; carfilzomib $45 \mathrm{mg} / \mathrm{m}^{2}, \mathrm{n}=2$; carfilzomib 56 $\mathrm{mg} / \mathrm{m}^{2}, \mathrm{n}=1$ ); four ( $4 \%$ ) of them had grade 3 toxicity. Five $(5 \%)$ patients needed antihypertensive treatment.

Seven patients $(6 \%)$ had pre-existing PN grade $1 / 2$ and two patients $(2 \%)$ had pre-existing grade $3 \mathrm{PN}$. During induction and consolidation therapy, 52 patients (47\%) developed PN. Grade $\geq 2 \mathrm{PN}$ events occurred in 23 patients $(20 \%)$ independently from carfilzomib dose; these events were clinically manageable (carfilzomib 27 $\mathrm{mg} / \mathrm{m}^{2}, \mathrm{n}=11$; carfilzomib $36 \mathrm{mg} / \mathrm{m}^{2}, \mathrm{n}=3$; carfilzomib 45 $\mathrm{mg} / \mathrm{m}^{2}, \mathrm{n}=6$; carfilzomib $\left.56 \mathrm{mg} / \mathrm{m}^{2} \mathrm{n}=3\right)$. Only one patient $(1 \%)$ reported grade $3 \mathrm{PN}$ (carfilzomib $27 \mathrm{mg} / \mathrm{m}^{2}$ ).

At least one serious AE (SAE) was reported in $43 \%$ of patients. In cohort 1, an SAE was reported in 21 (42\%) patients, in cohort 2 in $8(40 \%)$ patients, in cohort 3 in 7 $(33 \%)$ patients, and in cohort 4 in $12(60 \%)$ patients.

As reported above, nine patients ( $8 \%$ ) discontinued treatment due to excessive toxicity: six patients during induction therapy, and three patients during consolidation therapy. In cohort 1 , four ( $8 \%$ ) patients went off protocol due to AE: one $(5 \%)$ patient in cohort 2 and four $(20 \%)$ patients in cohort 4 . Table 5 shows an analysis of treat- ment adherence to protocol. During consolidation treatment, normal completion rate for carfilzomib and dexamethasone was similar to induction treatment whereas this was higher for thalidomide, probably due to the lower dose of thalidomide during consolidation treatment. A higher percentage of patients prematurely discontinued treatment at the highest dose level of carfilzomib (5 patients, $30 \%)$. Four patients $(20 \%)$ had excessive toxicity

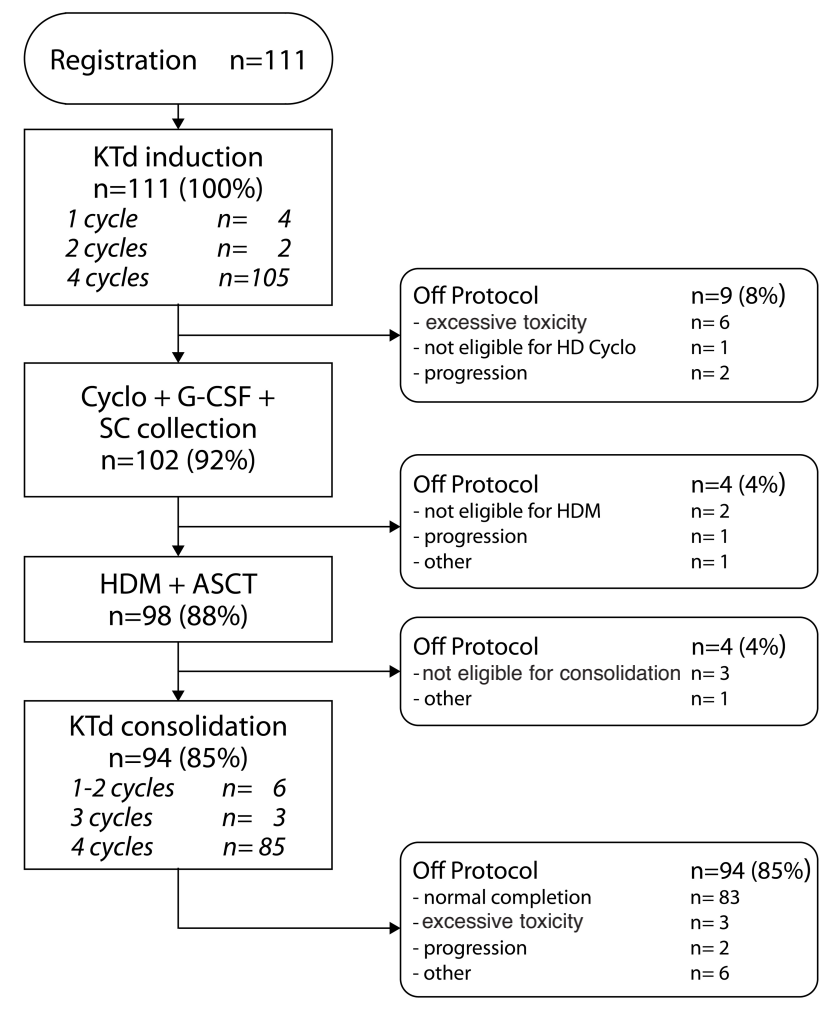

Figure 1. Consort diagram. Cyclo: cyclophosphamide; G-CSF: granulocyte colony-stimulating factor; HD: high dose; SC: stem cell. Ktd: carfilzomib, thalidomide and dexamethasone; n: number: HDM + ASCT: high-dose melphalan + autologous stem cell transplantation.

Table 2. Response after induction, after high-dose melphalan (HDM) and after consolidation therapy.

\begin{tabular}{|c|c|c|c|c|c|}
\hline Dosing level cariflzomib & $20 / 27 \mathrm{mg} / \mathrm{m}^{2}$ & $20 / 36 \mathrm{mg} / \mathrm{m}^{2}$ & $20 / 45 \mathrm{mg} / \mathrm{m}^{2}$ & $20 / 56 \mathrm{mg} / \mathrm{m}^{2}$ & All patients \\
\hline Patients, $n$ & 50 & 20 & 21 & 20 & 111 \\
\hline $\begin{array}{l}\text { Response after induction } \\
\text { SCR } \\
\geq \mathrm{CR} \\
\geq \mathrm{VGPR} \\
\geq \mathrm{PR}\end{array}$ & $\begin{array}{c}4(8) \\
8(16) \\
27(54) \\
45(90)\end{array}$ & $\begin{array}{c}1(5) \\
5(25) \\
16(80) \\
20(100)\end{array}$ & $\begin{array}{c}0(0) \\
3(14) \\
13(62) \\
20(95)\end{array}$ & $\begin{array}{c}1(5) \\
4(20) \\
16(80) \\
18(90)\end{array}$ & $\begin{array}{c}6(5) \\
20(18) \\
72(65) \\
103(93)\end{array}$ \\
\hline $\begin{array}{l}\text { Response after HDM, } n \text { ( } \\
\text { SCR } \\
\geq \text { CR } \\
\geq \text { VGPR } \\
\geq \text { PR }\end{array}$ & $\begin{array}{l}5(10) \\
12(24) \\
32(64) \\
46(92)\end{array}$ & $\begin{array}{c}2(10) \\
7(35) \\
17(85) \\
20(100)\end{array}$ & $\begin{array}{c}3(14) \\
9(43) \\
19(90) \\
20(95)\end{array}$ & $\begin{array}{c}1(5) \\
6(30) \\
18(90) \\
18(90)\end{array}$ & $\begin{array}{l}11(10) \\
34(31) \\
86(77) \\
104(94)\end{array}$ \\
\hline $\begin{array}{l}\text { Response after consolida } \\
\text { sCR } \\
\geq \text { CR } \\
\geq \text { VGPR } \\
\geq \text { PR }\end{array}$ & $\begin{array}{l}17(34) \\
28(56) \\
40(80) \\
46(92)\end{array}$ & $\begin{array}{c}4(20) \\
15(75) \\
18(90) \\
20(100)\end{array}$ & $\begin{array}{l}8(38) \\
14(67) \\
20(95) \\
20(95)\end{array}$ & $\begin{array}{l}4(20) \\
13(65) \\
18(90) \\
18(90)\end{array}$ & $\begin{array}{c}33(30) \\
70(63) \\
96(86) \\
104(94)\end{array}$ \\
\hline
\end{tabular}

n: number; sCR: stringent complete remission; CR: complete remission; VGPR: very good partial response; PR: partial response. 
and two patients $(10 \%)$ asked to discontinue treatment (Online Supplementary Table S2).

\section{Discussion}

Results of the first three dose levels of this phase II trial have been published before. ${ }^{11}$ In this paper, we discuss the results of four dose levels of carfilzomib. As reported above, treatment with KTd for induction and consolidation in transplant eligible patients with NDMM is safe, tolerable and effective. We included the additional cohort with the highest dose level of $56 \mathrm{mg} / \mathrm{m}^{2}$, based on the hypothesis that a higher dose level induces a higher response rate. ${ }^{12,16}$ Response after induction was high, with $65 \%$ of patients reaching at least VGPR, increasing to $86 \%$ after consolidation therapy. CR rate after consolidation was high at $63 \%$. Response (i.e. $>$ CR) after consolidation at the three higher dose levels (20/36, 20/45, 20/56) was better than at the lowest dose level (20/27); however, the small sample size and the non-randomized design of the study preclude firm conclusions about superiority of the highest dose levels. In the ARROW trial, 478 patients with RRMM were randomized between treatment with carfilzomib twice a week $27 \mathrm{mg} / \mathrm{m}^{2}$ or once weekly $70 \mathrm{mg} / \mathrm{m}^{2}$. PFS was higher with once weekly $70 \mathrm{mg} / \mathrm{m}^{2}$ than with twice weekly $27 \mathrm{mg} / \mathrm{m}^{2}$ (11.2 months vs. 7.6 months). ${ }^{20}$ These data and our data (based on response) suggest that a dose of at least $36 \mathrm{mg} / \mathrm{m}^{2}$ twice weekly (which equals 70 $\mathrm{mg} / \mathrm{m}^{2}$ once weekly) would be the preferred dose.

An important remaining question relates to the efficacy of this regimen in high-risk patients. In this trial with lim-

Table 3. Response after consolidation therapy according to risk status and R-ISS.

\begin{tabular}{lcccccc} 
& Standard risk* & High-risk* & R-ISS 1 & R-ISS 2 & R-ISS 3 & Total \\
Patients, n & 46 & 43 & 26 & 65 & 111 & 10 \\
SCR, n (\%) & $16(35)$ & $9(21)$ & $10(38)$ & $19(29)$ & $0(0)$ & $33(30)$ \\
$\geq$ CR, n (\%) & $31(67)$ & $25(58)$ & $19(73)$ & $37(57)$ & $6(60)$ & $70(63)$ \\
$\geq$ VGPR, n (\%) & $40(87)$ & $36(84)$ & $24(92)$ & $54(83)$ & $9(90)$ & $96(86)$ \\
$\geq$ PR, n (\%) & $44(96)$ & $38(88)$ & $26(100)$ & $58(91)$ & $10(100)$ & $104(94)$ \\
\hline
\end{tabular}

*High-risk:t(4;14) and/or 17p- and/or add1q cytogenetic abnormalities and/or ISS stage 3 disease.Standard risk: the remaining patients with available cytogenetics and ISS stage n: number; ISS: International Staging System; R-ISS: Revised International Staging System; sCR: stringent complete remission; CR: complete remission;VGPR: very good partial response; PR: partial response.
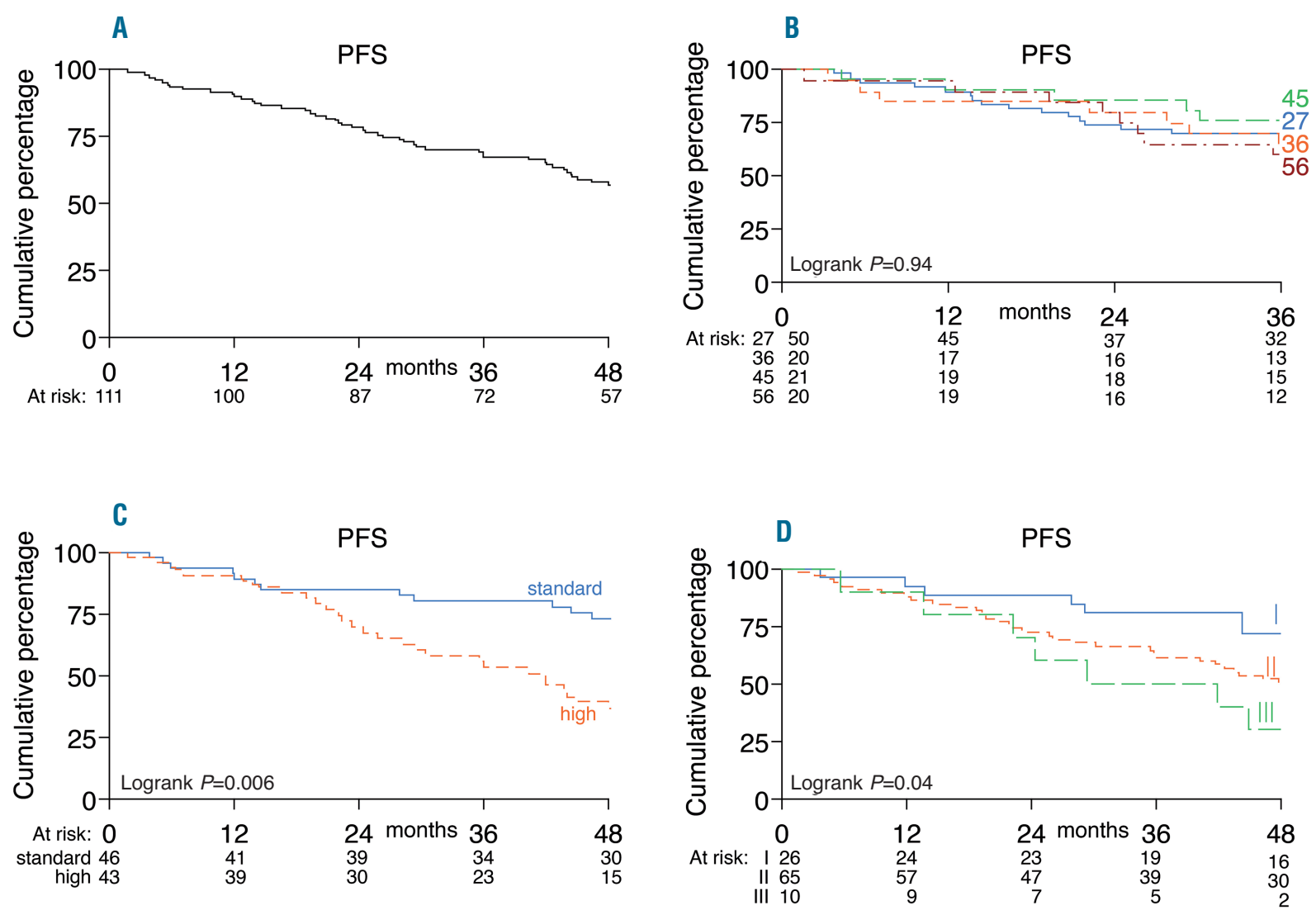

Figure 2. Kaplan-Meier curves of progression-free survival (PFS). (A) PFS in all 111 patients. (B) PFS per dose level. (C) PFS according to risk status. (D) PFS according to Revised-International Staging System. 
ited numbers, the negative impact of high-risk cytogenetics was not abrogated by carfilzomib. ${ }^{21}$ At the same time, overall risk status, based on cytogenetics and ISS stage, was not significantly associated with response. However, high-risk patients and patients with a higher R-ISS score had a significantly worse PFS. Median PFS and OS for all patients were 58 months and 83 months, respectively. These data show that treatment with KTd is effective as front-line treatment of transplant eligible patients with NDMM. Also, this regimen had no effect on stem cell mobilization and collection, with the exception of two patients in whom stem cell collection failed. Several phase
II trials have investigated treatment with carfilzomib in NDMM using different regimens. ${ }^{12-15}$ For example, in the CYKLONE trial, cyclophosphamide was added to the KTd regimen; this showed a comparable ORR of $91 \%$ and a PFS at 24 months of $76 \%$. In this study, MTD was $20 / 36$ $\mathrm{mg} / \mathrm{m}^{2}{ }^{213}$ In comparison, in the Carthadex trial, dose levels of $45 \mathrm{mg} / \mathrm{m}^{2}$ and $56 \mathrm{mg} / \mathrm{m}^{2}$ were well tolerated without additional toxicity compared to dose levels $27 \mathrm{mg} / \mathrm{m}^{2}$ and $36 \mathrm{mg} / \mathrm{m}^{2}$. The number of patients going off treatment due to excessive toxicity was low: 9 out of 111 patients (8\%). Our data show that efficacy and safety are comparable at dose levels $36 \mathrm{mg} / \mathrm{m}^{2}$ and upward. Main grade $3 / 4$ non-
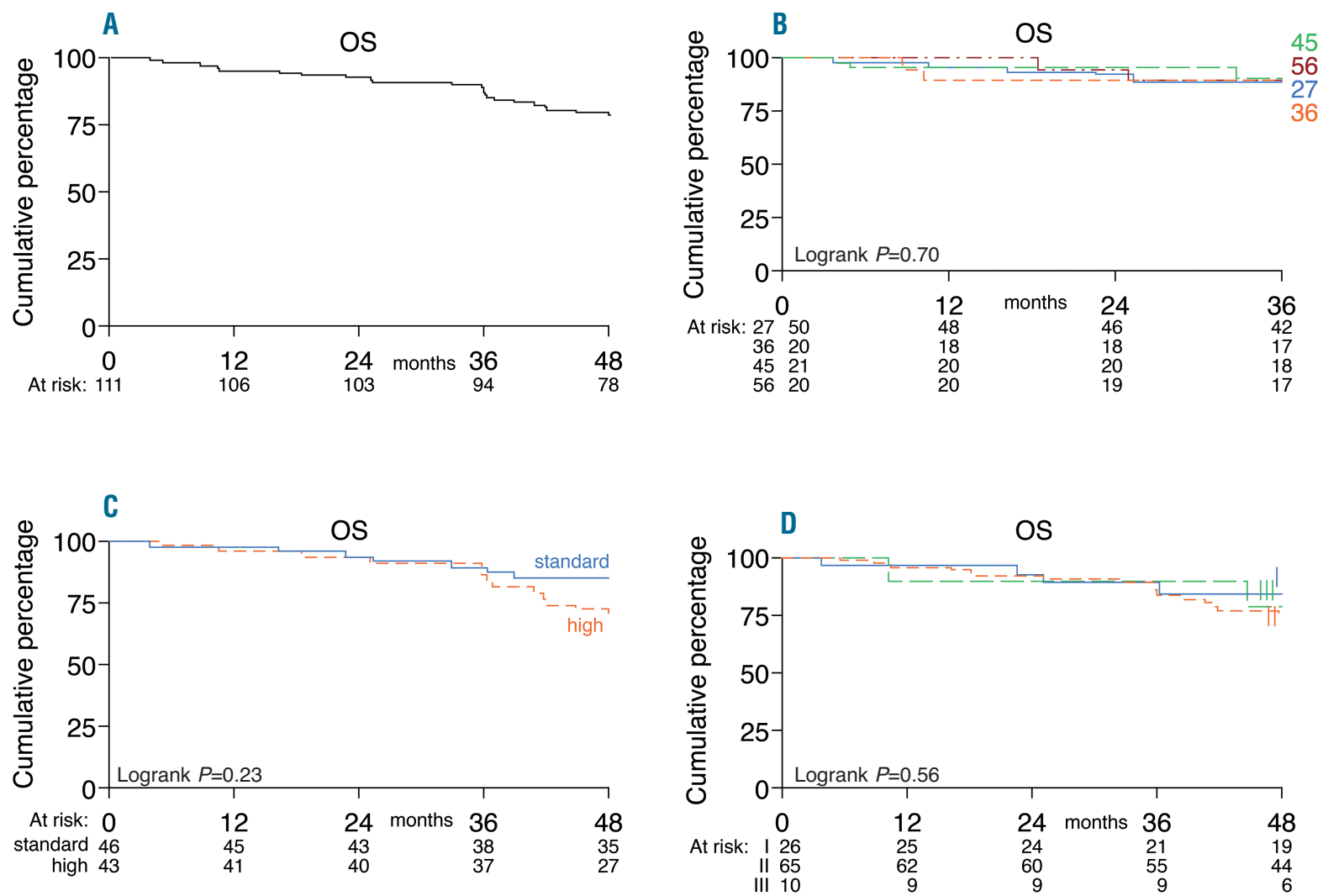

Figure 3. Kaplan-Meier curves overall survival (OS). (A) OS in all 111 patients. (B) OS per dose level. (C) OS according to risk status. (D) OS according to RevisedInternational Staging System.

Table 4. Cardiac adverse events between dose levels.

\begin{tabular}{|c|c|c|c|c|c|c|c|c|}
\hline \multirow[b]{2}{*}{ Cardiac toxicity, n (\%) } & \multicolumn{2}{|c|}{$20 / 27 \mathrm{mg} / \mathrm{m}^{2}, \mathrm{n}=50$} & \multicolumn{2}{|c|}{$20 / 36 \mathrm{mg} / \mathrm{m}^{2}, \mathrm{n}=20$} & \multicolumn{2}{|c|}{$20 / 45 \mathrm{mg} / \mathrm{m}^{2}, \mathrm{n}=21$} & \multicolumn{2}{|c|}{$20 / 56 \mathrm{mg} / \mathrm{m}^{2}, \mathrm{n}=20$} \\
\hline & Grade 1/2 & Grade $3 / 4$ & Grade 1/2 & Grade $3 / 4$ & Grade 1/2 & Grade $3 / 4$ & Grade 1/2 & Grade $3 / 4$ \\
\hline Acute coronary syndrome & $0(0)$ & $0(0)$ & $1(5)$ & $0(0)$ & $0(0)$ & $0(0)$ & $0(0)$ & $0(0)$ \\
\hline Atrial flutter & $1(2)$ & $0(0)$ & $0(0)$ & $0(0)$ & $0(0)$ & $0(0)$ & $0(0)$ & $0(0)$ \\
\hline Atrial fibrillation & $1(2)$ & $0(0)$ & $0(0)$ & $0(0)$ & $0(0)$ & $0(0)$ & $0(0)$ & $0(0)$ \\
\hline Angina pectoris & $3(6)$ & $0(0)$ & $1(5)$ & $0(0)$ & $2(10)$ & $1(5)$ & $1(5)$ & $0(0)$ \\
\hline Congestive heart failure & $1(2)$ & $2(4)$ & $1(5)$ & $0(0)$ & $0(0)$ & $0(0)$ & $0(0)$ & $1(5)$ \\
\hline Dyspnea & $0(0)$ & $1(2)$ & $0(0)$ & $0(0)$ & $0(0)$ & $0(0)$ & $0(0)$ & $0(0)$ \\
\hline Palpitations & $1(2)$ & $0(0)$ & $1(5)$ & $0(0)$ & $1(5)$ & $0(0)$ & $0(0)$ & $0(0)$ \\
\hline Pericardial fluid & $0(0)$ & $0(0)$ & $0(0)$ & $0(0)$ & $0(0)$ & $0(0)$ & $1(5)$ & $0(0)$ \\
\hline Total of cardiac events & $7(14)$ & $3(6)$ & $4(20)$ & $0(0)$ & $3(14)$ & (5) & $1(5)$ & $1(5)$ \\
\hline
\end{tabular}

n: number. 
Table 5. Adherence to treatment protocol during induction and consolidation.

\begin{tabular}{|c|c|c|}
\hline Kolom1 & $\begin{array}{l}\text { Induction } \\
(\mathrm{N}=111)\end{array}$ & $\begin{array}{l}\text { Consolidation } \\
(\mathrm{N}=94)\end{array}$ \\
\hline \multicolumn{3}{|l|}{ Carfilzomib } \\
\hline Normal completion & $68(61)$ & $61(55)$ \\
\hline $\begin{array}{l}\text { Dose delay, reduction and/or } \\
\text { interruption }\end{array}$ & $37(33)$ & $24(22)$ \\
\hline Premature stop & $6(5)$ & $9(10)$ \\
\hline \multicolumn{3}{|l|}{ Thalidomide } \\
\hline Normal completion & $54(49)$ & $63(67)$ \\
\hline $\begin{array}{l}\text { Dose delay, reduction and/or } \\
\text { interruption }\end{array}$ & $42(38)$ & $8(9)$ \\
\hline Premature stop & $15(14)^{\mathrm{a}}$ & $23(24)^{b}$ \\
\hline \multicolumn{3}{|l|}{ Dexamethasone } \\
\hline Normal completion & $85(77)$ & $66(70)$ \\
\hline $\begin{array}{l}\text { Dose delay, reduction and/or } \\
\text { interruption }\end{array}$ & 20 (18) & $18(19)$ \\
\hline Premature stop & $6(5)$ & $10(11)$ \\
\hline
\end{tabular}

ancluding 9 patients who received no thalidomide during induction cycle 4 . 'Including 14 patients who received no thalidomide during consolidation cycle 4. n: number.

hematologic toxicity consisted of infections, respiratory, skin, and vascular disorders. The rate of cardiac AE was low in this trial. Five patients $(5 \%)$ experienced grade 3 cardiac AE, including congestive heart failure, dyspnea and chest pain. This is comparable to other trials investigating carfilzomib in NDMM. ${ }^{12-14}$ The rate of grade $3 / 4$ cardiac toxicity is slightly higher in RRMM, most likely because patients are older and due to previous treatment. ${ }^{9,10}$ However, the limited number of patients preclude firm conclusions about safety regarding cardiac events between the different dose levels. Jakubowiak et al. performed a phase I/II trial of carfilzomib combined with lenalidomide and dexamethasone (CRd). In this trial, patients not proceeding to ASCT continued treatment with CRd beyond eight cycles with a median of 12 cycles. PFS at 24 months was $92 \% .{ }^{12}$ However, thalidomide remains a valuable treatment option in many countries, due to its availability and low costs, and offers an excellent alternative to treatment with lenalidomide.

Recently, several trials have been performed in patients with NDMM, using alternative schedules for induction and consolidation. The Intergroupe Francophone du Myélome (IFM) performed a phase II trial of lenalidomide combined with bortezomib and dexamethasone (RVD) for induction and consolidation. PFS at three years was $77 \%$ and CR was $58 \%$. Most common toxicities were grade $1 / 2 \mathrm{PN}$ in $55 \%{ }^{22}$ In the EMN02 trial, VCD for induction was followed by VRD for consolidation treatment. CR rate was $55 \%$ and PFS not reached at 60 months. ${ }^{23}$ Although it should be taken into account that this is a cross comparison between trials, the Carthadex trial efficacy data are similar with median PFS of 58 months and CR rate of $63 \%$, and acceptable toxicity. Moreover, the combination of carfilzomib, thalidomide and dexamethasone is an affordable treatment regimen. These data suggest that KTd is an effective and safe induction and consolidation regimen in newly diagnosed MM.

In conclusion, the combination of carfilzomib, thalidomide and low-dose dexamethasone appears highly efficacious and safe in transplant-eligible patients with NDMM across all dose levels with manageable toxicities. Consolidation therapy after ASCT results in a major improvement in response. In addition, we observed that higher dose levels of carfilzomib $\left(36-56 \mathrm{mg} / \mathrm{m}^{2}\right)$ result in better response rates after consolidation therapy. Current studies in newly diagnosed MM patients are performed using $36 \mathrm{mg} / \mathrm{m}^{2}$ twice weekly. The preferred dose to be used in practice would be $36 \mathrm{mg} / \mathrm{m}^{2}$ twice weekly (or 70 $\mathrm{mg} / \mathrm{m}^{2}$ once weekly), which we would recommend based on our carthadex response data. Results of cohort 5 , in which patients were treated with eight instead of four induction cycles, will follow in the near future.

Further randomized, prospective studies are needed to confirm these data and determine the place for carfilzomib in the treatment of patients with NDMM.

\section{Acknowledgments}

This trial was supported by funding from Onyx Pharmaceuticals, Inc., an Amgen subsidiary.

\section{References}

1. Lahuerta JJ, Mateos MV, Martinez-Lopez J, et al. Influence of pre- and post-transplantation responses on outcome of patients with multiple myeloma: sequential improvement of response and achievement of complete response are associated with longer survival. J Clin Oncol. 2008;26(35):5775-5782.

2. Cavo M, Brioli A, Tacchetti P, et al. Role of consolidation therapy in transplant eligible multiple myeloma patients. Semin Oncol. 2013;40(5):610-617.

3. Niesvizky R, Richardson PG, Rajkumar SV, et al. The relationship between quality of response and clinical benefit for patients treated on the bortezomib arm of the international, randomized, phase 3 APEX trial in relapsed multiple myeloma. Br J Haematol. 2008;143(1):46-53.

4. Harousseau JL, Dimopoulos MA, Wang M, et al. Better quality of response to lenalidomide plus dexamethasone is associated with improved clinical outcomes in patients with relapsed or refractory multiple myeloma. Haematologica. 2010;95(10):1738-1744

5. van de Velde HI, Liu X, Chen G, et al. Complete response correlates with longterm survival and progression-free survival in high-dose therapy in multiple myeloma. Haematologica. 2007;92(10):1399-1406

6. Cavo M, Tacchetti P, Patriarca F, et al. Bortezomib with thalidomide plus dexamethasone compared with thalidomide plus dexamethasone as induction therapy before, and consolidation therapy after, double autologous stem-cell transplantation in newly diagnosed multiple myeloma: a randomised phase 3 study. Lancet. 2010; 376(9758):2075-2085.

7. Rosinol L, Oriol A, Teruel AI, et al. Superiority of bortezomib, thalidomide, and dexamethasone (VTD) as induction pretransplantation therapy in multiple myeloma: a randomized phase 3 PETHEMA/GEM study. Blood. 2012;120(8):15891596.

8. Moreau P, Hulin C, Macro M, et al. VTD is superior to VCD prior to intensive therapy in multiple myeloma: results of the prospective IFM2013-04 trial. Blood. 2016; 127(21):2569-2574

9. Stewart AK, Rajkumar SV, Dimopoulos $\mathrm{MA}$, et al. Carfilzomib, lenalidomide, and dexamethasone for relapsed multiple myeloma. N Engl J Med. 2015;372(2):142152.

10. Dimopoulos MA, Moreau P, Palumbo A, et al. Carfilzomib and dexamethasone versus bortezomib and dexamethasone for patients with relapsed or refractory multiple myeloma (ENDEAVOR): a randomised, phase 3 , open-label, multicentre study. 
Lancet Oncol. 2016;17(1):27-38.

11. Sonneveld P, Asselbergs E, Zweegman S, et al. Phase 2 study of carfilzomib, thalidomide, and dexamethasone as induction/consolidation therapy for newly diagnosed multiple myeloma. Blood. 2015; 125(3):449-456.

12. Jakubowiak AJ, Dytfeld D, Griffith KA, et al. A phase $1 / 2$ study of carfilzomib in combination with lenalidomide and low-dose dexamethasone as a frontline treatment for multiple myeloma. Blood. 2012;120(9): 1801-1809.

13. Mikhael JR, Reeder CB, Libby EN, et al. Phase Ib/II trial of CYKLONE (cyclophosphamide, carfilzomib, thalidomide and dexamethasone) for newly diagnosed myeloma. Br J Haematol. 2015;169(2):219-227.

14. Bringhen S, Petrucci MT, Larocca A, et al. Carfilzomib, cyclophosphamide, and dexamethasone in patients with newly diagnosed multiple myeloma: a multicenter, phase 2 study. Blood. 2014;124(1):63-69.

15. Moreau P, Kolb B, Attal M, et al. Phase 1/2 study of carfilzomib plus melphalan and prednisone in patients aged over 65 years with newly diagnosed multiple myeloma. Blood. 2015;125(20):3100-3104.

16. Papadopoulos KP, Siegel DS, Vesole DH, et al. Phase I study of 30-minute infusion of carfilzomib as single agent or in combination with low-dose dexamethasone in patients with relapsed and/or refractory multiple myeloma. J Clin Oncol. 2015; 33(7):732-739.

17. Larocca A, Cavallo F, Bringhen S, et al. Aspirin or enoxaparin thromboprophylaxis for patients with newly diagnosed multiple myeloma treated with lenalidomide. Blood. 2012;119(4):933-939

18. Kumar S, Paiva B, Anderson KC, et al International Myeloma Working Group consensus criteria for response and minimal residual disease assessment in multiple myeloma. Lancet Oncol. 2016;17(8):e328e346.

19. Dueck AC, Mendoza TR, Mitchell SA, et al. Validity and Reliability of the US National Cancer Institute's Patient-Reported Outcomes Version of the Common Terminology Criteria for Adverse Events (PRO-CTCAE). JAMA Oncol. 2015; 1(8):1051-1059.

20. Moreau P, Mateos MV, Berenson JR, et al. Once weekly versus twice weekly carfilzomib dosing in patients with relapsed and refractory multiple myeloma (A.R.R.O.W.): interim analysis results of a randomised, phase 3 study. Lancet Oncol. 2018; 19(7):953-964.

21. Goldschmidt H, Lokhorst HM, Mai EK, et al. Bortezomib before and after high-dose therapy in myeloma: long-term results from the phase III HOVON-65/GMMG-HD4 trial. Leukemia. 2018:32(2):383-390

22. Roussel M, Lauwers-Cances V, Robillard N, et al. Front-line transplantation program with lenalidomide, bortezomib, and dexamethasone combination as induction and consolidation followed by lenalidomide maintenance in patients with multiple myeloma: a phase II study by the Intergroupe Francophone du Myelome. J Clin Oncol. 2014;32(25):2712-2717.

23. Sonneveld P, Juni 2018. Consolidation followed by maintenance vs. maintenance alone in newly diagnosed, transplant eligible multiple myeloma: a randomized phase 3 study of the European Myeloma Network (EMN02/HO95 MM TRIAL). Abstract presented at the EHA meeting, Stockholm, Sweden. Abstract retrieved from https://learningcenter.ehaweb.org/ eha/2018/stockholm/214488/pieter.sonneveld.consolidation.followed.by.maintenance.vs.maintenance.alone.in.html. Abstract \# S108. 